\title{
CONSTITUTIVE MODEL FOR CEMENTED QUICK CLAY IN DEEP-MIX STABILIZATION
}

\section{PANCRAS MUGISHAGWE BUJULU AND GUSTAV GRIMSTAD}

(Received 12, October 2011; Revision Accepted 6, March 2012)

\begin{abstract}
Based on experimental results of a laboratory study on lime and cement stabilized quick clay, carried out at NTNU, Norway, a two yield surface constitutive model has been formulated. The model reproduces the mechanical behavior of the stabilized soil in the p'-q stress space. In the stress space the two yield surfaces appear as a "cap" and a "wedge" respectively. The formulated model "QUICKSTAB" has satisfactorily been able to simulate the overall geomechanical behaviour of stabilized quick clay and it agrees very well with the results established by the laboratory study. Typical model parameter values are also presented herein for various soil-binder mixtures. An extensive parametric study has been recommended to thoroughly explain the behavior of the model, including tests following different stress paths and extension of the study to include anisotropic cap-surface.
\end{abstract}

KEYWORDS: Constitutive model, quick clay, hardening rule, yield surface, destructuration

\section{INTRODUCTION}

Stabilization process involves complete remoulding of the soil and mixing the binder materials in. Remoulding of the extremely sensitive quick clay changes it into a viscous fluid before the binder material is added. The eventual engineering properties of the stabilized material depend on the fabric and particle cementation resulting from the chemical reaction of the binders. Stabilized clays have been shown by many researches (e.g. Balasubramaniam \& Buensuceso (1989); Broms, 1999; Kivelö \& Broms, 1999; Baker, 2000; Kwan et al., 2005) to closely behave similar to other structured and over-consolidated soils. Such soils display a substantial amount of intrinsic stiffness and strength when subjected to an external loading. When the external load exceeds the bond strength, the bonds break as the material yields leading further to a complete collapse of the microstructure. Prediction of the mechanical behaviour of engineering geo-materials requires a well formulated constitutive model that can best capture the non-uniformity, heterogeneity and anisotropy of soils, and some uncertainties in geotechnical assumptions.

This paper presents a constitutive model (QUICKSTAB) for stabilized quick clay, which has been proposed based on the results of an investigation on stabilization of quick clay and the potential for utilization of wastepaper sludge ash for deep-mix stabilization of quick clay. The study was carried out at NTNU, Norway and is explained more in Bujulu (2008). The model takes into account the actual mechanical properties of the stabilized material and simulates fairly well the overall behavior of this material obtained from the laboratory experiments. Typical parameter values are also presented for various binder mixtures.

\section{MODEL CONCEPT}

A multiple yield surface model is proposed to model the mechanical behaviour of the stabilized soil material. In the p'-q stress space the two yield mechanisms will appear as a "cap" and a

Pancras Mugishagwe Bujulu, Lecturer, College of Engineering and Technology, University of Dar es Salaam, Tanzania

Gustav Grimstad, Researcher, Norwegian University of Science and Technology, NTNU, Trondheim, Norway. 
"wedge" respectively. The cap is mainly meant to model the volumetric (oedometric) behaviour and the wedge is meant to model the deviatoric behaviour. The cap is identical to the isotropic cap used in the Hardening Soil Model

(Brinkgreve et al., 2006). However, with a relevant rotational rule, rotation of the cap surface may be introduced in a similar manner to the S-Clay1 model (Wheeler et. al., 2003). The wedge yield criterion, or cone surface in full stress space, is formulated as proposed by Søreide (2003) and Dafalias \& Manzari (2004). In
Figure 1 the model principle is shown in the p'-q space.

\section{MATHEMATICAL FORMULATION}

The model is formulated in the triaxial stress space. The model principle is shown in the p'-q space in Figure 1. Formulation is discussed under three sub-sections, namely, the cap yield surface, hardening rules for the cap and cone yield and potential surface

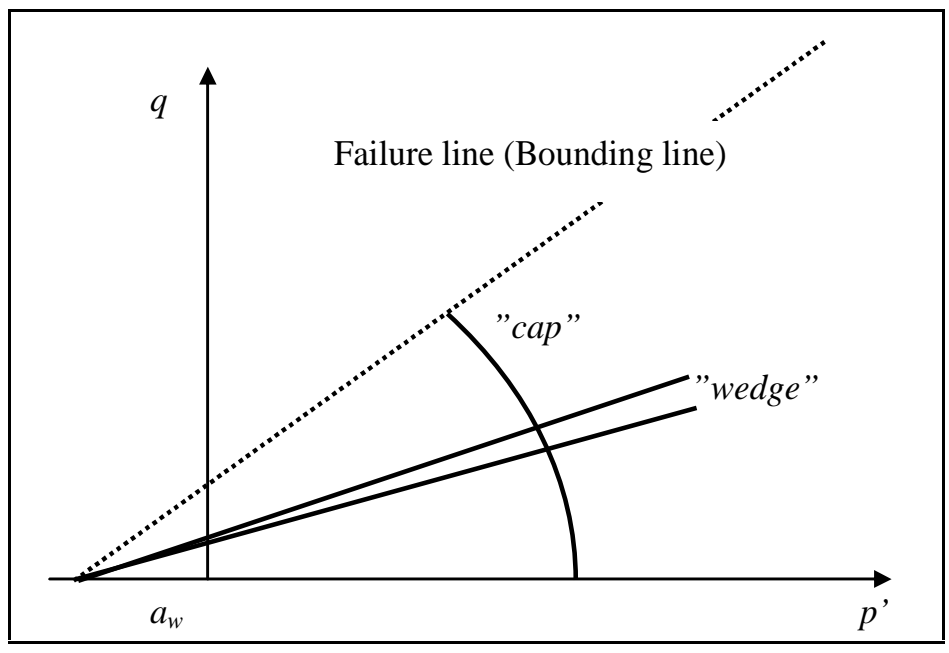

Figure 1: Model principle, visualized in p'-q space

\section{Cap Yield Surface}

In equation (1) the cap surface is given as:

$$
F_{c}=q^{2}+\mathrm{M}^{2} \cdot\left(\left(p^{\prime}+a_{c}\right)^{2}-p_{m}{ }^{\prime 2}\right)=0
$$

where M (Greek capital ) is an internal parameter related to the earth pressure coefficient under virgin loading, $\mathrm{K}_{0}{ }^{\mathrm{NC}} ; \mathrm{p}_{\mathrm{m}}$ ' is the size of the cap and $a_{c}$ is the attraction for the cap. It may be shown, due to the strain requirement in oedometric condition and through an associated flow rule, that $M$ will be given by Equation (2), assuming infinite elastic stiffness. $\mathrm{K}_{0}{ }^{\mathrm{NC}}$ is in this case obtained by including the $a_{c}$ term for the stresses. $M$ is easiest obtained by a stress condition in which $\mathrm{a}_{\mathrm{c}}<<\mathrm{p}$ '.

$\mathrm{M} \approx \sqrt{\frac{3}{2} \cdot \frac{3\left(1-K_{0}^{N C}\right)}{1+2 K_{0}^{N C}}}$

If Jaky's formula is used, M might be given directly by the friction angle.

\section{Hardening Rules for the Cap}

Two hardening rules are used for the cap surface. Firstly, an isotropic hardening rule which, as opposed to the models like the Modified Cam Clay Model (Roscoe and Burland, 1968), includes the possibility for a constant term. The expression will then take the form:

$\frac{d p_{m}{ }^{\prime}}{d \lambda_{c}}=\left(p_{m}{ }^{\prime} \cdot \frac{1}{\zeta}+Z_{a}\right) \cdot \frac{\partial F_{c}}{\partial p^{\prime}}$

where $\zeta$ and $\mathrm{Za}$ are parameters controlling the hardening of the cap.

The second cap hardening rule is the attraction softening. Under oedometeric condition (isolating the cap behavior) two types of attraction softening may generally be experienced. Type I may be given by a destructuration rule, see e.g. Karstunen et al. (2006). In this case the observed stiffness in the NC domain is experienced to be lower than the one for unbounded material (we may scale our stress down by a structural 
parameter). The structure is reduced during straining (destructuration rule), and for large strain the unbounded (remolded) stiffness is experienced. Type II is associated with the loss of the $a_{c}$ term in the yield criterion for the cap. The parameter $\mathrm{a}_{\mathrm{c}}$ will in this case scale our stress upwards, giving higher stiffness than for the unbounded material. A softening rule for the attraction, $a_{c}$, will then give us the proper variation of stiffness with strain. In Figure 2 these two types of stiffness degradation are shown. Natural quick clay shows type I of softening while stabilized quick clay shows type II (ref. Figure 3).

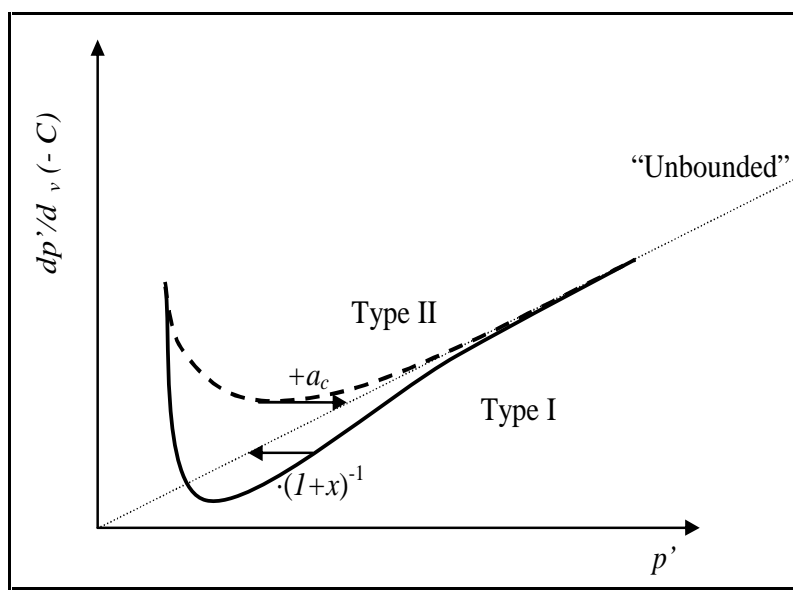

Figure 2: Two types of stiffness degradation
Hence we may propose the following softening rule for the attraction due to the cap type plasticity.

$\frac{d a_{c}}{d \lambda_{c}}=-a_{c} \cdot \mu_{a c} \cdot \frac{\partial F_{c}}{\partial p^{\prime}}$

where ${ }_{a c}$ is a hardening parameter.

The $\mathrm{C}$ term is added to the vertical axis label (Figure 2) to take care of the "attraction" in the oedometer test results for stabilized quick clay (ref. Figure 3)

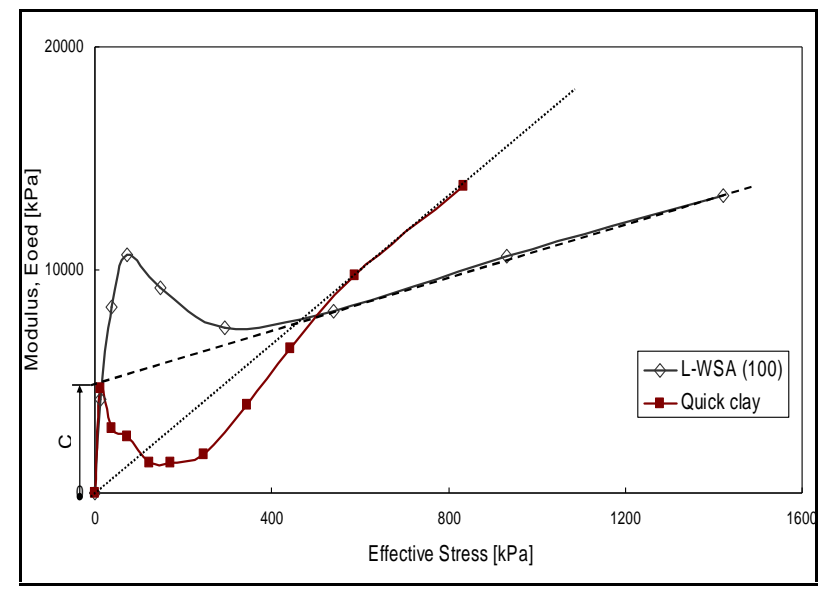

Figure 3: Typical oedometer modulus curves for natural and stabilized quick clay

\section{Cone yield and potential surface}

The cone yield surface will in the p'-q stress space appear as a wedge. Equation (5) gives an expression for the wedge yield surface.

$$
F_{w}=\left|q-\left(p^{\prime}+a_{w}\right) \cdot \alpha\right|-m \cdot\left(p^{\prime}+a_{w}\right)=0
$$

where $\alpha$ is the rotation of the wedge in the $p-q$ space; $m$ is the size of the wedge; $a_{w}$ is the attraction for the wedge (see

Figure 1).

The size parameter $m$ will be a small number and will be given a default value of $0.01 M_{c, f .}$ Where $M_{c, f}$ is the maximum value of $q /\left(p^{\prime}+a_{w}\right)$ in a triaxial compression test. The potential surface is not directly needed; only its derivatives with respect to the stress components (Equation (6)) are used.

$$
\left[\begin{array}{c}
\frac{\partial Q_{w}}{\partial p^{\prime}} \\
\frac{\partial Q_{w}}{\partial q}
\end{array}\right]=\left[\begin{array}{c}
f_{Q}\left(q, p^{\prime}, a_{w}\right) \\
\frac{\partial F_{w}}{\partial q}
\end{array}\right]
$$

where $f_{Q}\left(q, p^{\prime}, a_{w}\right)$ is a dilatancy/contractancy parameter, which in general may be stress dependent.

Equation (7) gives a suggestion for a possible mathematical expression for $f_{Q}$. In contrast to other models, where a mobilization formulation is used, this is independent of $q$. 
$f_{Q}=\frac{a_{w}}{p^{\prime}+a_{w}} \cdot \frac{\partial F_{w}}{\partial p^{\prime}}$

\section{Hardening Rules for the Wedge}

The kinematic hardening rule for the wedge

$$
\frac{d \alpha}{d \lambda_{w}}=f_{\alpha}\left(q, p^{\prime}, a_{w}, \frac{\partial F_{w}}{\partial q}\right)
$$

where $\mathrm{f}_{\alpha}$ may be determined by curve-fitting with the laboratory experiments or by choosing some basic functions.

For $f_{\alpha}$ we will have the following requirements

$$
\begin{aligned}
& f_{\alpha}=0 \quad \text { when } \frac{q}{p^{\prime}+a_{w}}=M_{f} \quad\left(\mathrm{M}_{\mathrm{f}} \text { is the failure criteria }\right) \\
& f_{\alpha} \rightarrow \infty \text { for stress reversal or initial shearing }
\end{aligned}
$$

The function given by equation (9) may be used in triaxial stress-strain space.

$$
\frac{d \alpha}{d \lambda_{w}}=\mu_{w} \cdot \frac{1}{\left(M_{c, f}+M_{e, f}\right) \cdot \frac{\partial F_{w}}{\partial q}} \cdot\left(\frac{q_{b}-q}{p^{\prime}+a_{w}}\right)^{2}
$$

where $\mathrm{q}_{\mathrm{b}}$ is the bounding deviatoric stress

In the triaxial shearing tests the material shows "attraction softening" (cohesion softening), ref. Figure 9. Equation (10) gives a mathematical expression for how this softening rule may look like.

$$
\frac{d a_{w}}{d \lambda_{w}}=-a_{w} \cdot \mu_{a w} \cdot\left|\frac{q}{p^{\prime}+a_{w}}\right|
$$

where aw is a hardening parameter.

\section{Elastic Properties}

For simplicity an isotropic elastic behaviour is chosen. As shown by Equation (11) below, the shear stiffness is assumed to be given by the Poisson ratio. This is done based on the oedometer tests.

$$
\begin{aligned}
& {\left[\begin{array}{l}
d p^{\prime} \\
d q
\end{array}\right]=\left[\begin{array}{cc}
K & 0 \\
0 & 3 G
\end{array}\right]\left[\begin{array}{l}
d \varepsilon_{v} \\
d \varepsilon_{q}
\end{array}\right]} \\
& K=\frac{1}{\kappa^{*}} \cdot p^{\prime}+\mathrm{K}_{a} \\
& G=K \cdot \frac{3(1-2 v)}{2(1+v)}
\end{aligned}
$$

where $\mathrm{K}^{\star}, \mathrm{K}_{\mathrm{a}}$ and $\mathrm{v}$ are the elastic input parameters

\section{LABORATORY DATA}

Four types of mixtures were investigated as shown in

Table 1. For sample preparation and testing methods the reader is referred to Bujulu (2008). Results from undrained triaxial compression and incremental loading oedometer tests for the four mixture types at 90 days curing period were used to calibrate the proposed model. The results are presented in the same plots with the respective simulation curves for comparison and model evaluation purposes; ref. Figure 4 to Figure 7. 
Table 1: Binder mix types

\begin{tabular}{clll}
\hline Mix 1 & L-WSA & $50: 50$ & $100 \mathrm{~kg} / \mathrm{m}^{3}$ \\
\hline Mix 2 & L-C & $50: 50$ & $100 \mathrm{~kg} / \mathrm{m}^{3}$ \\
\hline Mix 3 & L-C-WSA & $37.5: 25: 37.5$ & $100 \mathrm{~kg} / \mathrm{m}^{3}$ \\
\hline Mix 4 & L-WSA & $50: 50$ & $150 \mathrm{~kg} / \mathrm{m}^{3}$ \\
\hline
\end{tabular}

\section{MODEL SIMULATION}

The material model is implemented in a numerical scheme, which allows for violation of several yield criteria. The rule for adding response from several yield criteria and plastic potential functions is called the Koiter rule
(Schanz et al., 1999). The scheme allows only the plastic multiplier for the violated yield criteria to be activated. Simulations for the different mixtures can be obtained by varying the parameter values. Typical material properties used for the reported simulations are given by

Table 2.

Table 2: Model parameters

\begin{tabular}{|c|c|c|c|c|c|c|c|c|c|c|c|c|}
\hline$\overline{M i x}$ & $\begin{array}{l}\mathrm{v} \\
\mathrm{pm}\end{array}$ & $\mathrm{K}^{*}$ & $\mathrm{~K}_{\mathrm{a}}$ & $\varphi$ & $a_{w 0}$ & $w$ & aw & $M$ & $a_{c 0}$ & $\zeta$ & Z & ac \\
\hline & $\overline{\mathrm{kPa}}$ & - & $\mathrm{kPa}$ & $\underline{0}$ & $\mathrm{kPa}$ & - & - & - & $\mathrm{kPa}$ & - & $\mathrm{kPa}$ & - \\
\hline 1 & $\begin{array}{l}.15 \\
340\end{array}$ & .0035 & 300 & 41 & 90 & 1500 & 20 & .94 & 330 & .19 & 2800 & 1.2 \\
\hline 2 & $\begin{array}{l}.12 \\
350\end{array}$ & .01 & 3400 & 44 & 120 & 3200 & 55 & 1.02 & 303 & .14 & 3800 & 48 \\
\hline 3 & $\begin{array}{l}.01 \\
350\end{array}$ & .019 & 2100 & 37 & 210 & 2000 & 60 & 1.05 & 320 & .18 & 5000 & 200 \\
\hline 4 & $\begin{array}{l}.15 \\
330\end{array}$ & .005 & 2000 & 42 & 120 & 2500 & 22 & 1.2 & 300 & .17 & 2600 & 5 \\
\hline
\end{tabular}

Figure 4 and Figure 6 show results from simulation of undrained triaxial shearing for different isotropic consolidation cell pressure. Figure 5 and Figure 7 show results form oedometer simulations. The simulation curves are plotted against the respective experimental data for calibration purposes. It can be seen that the model simulations fit well to the laboratory data. 

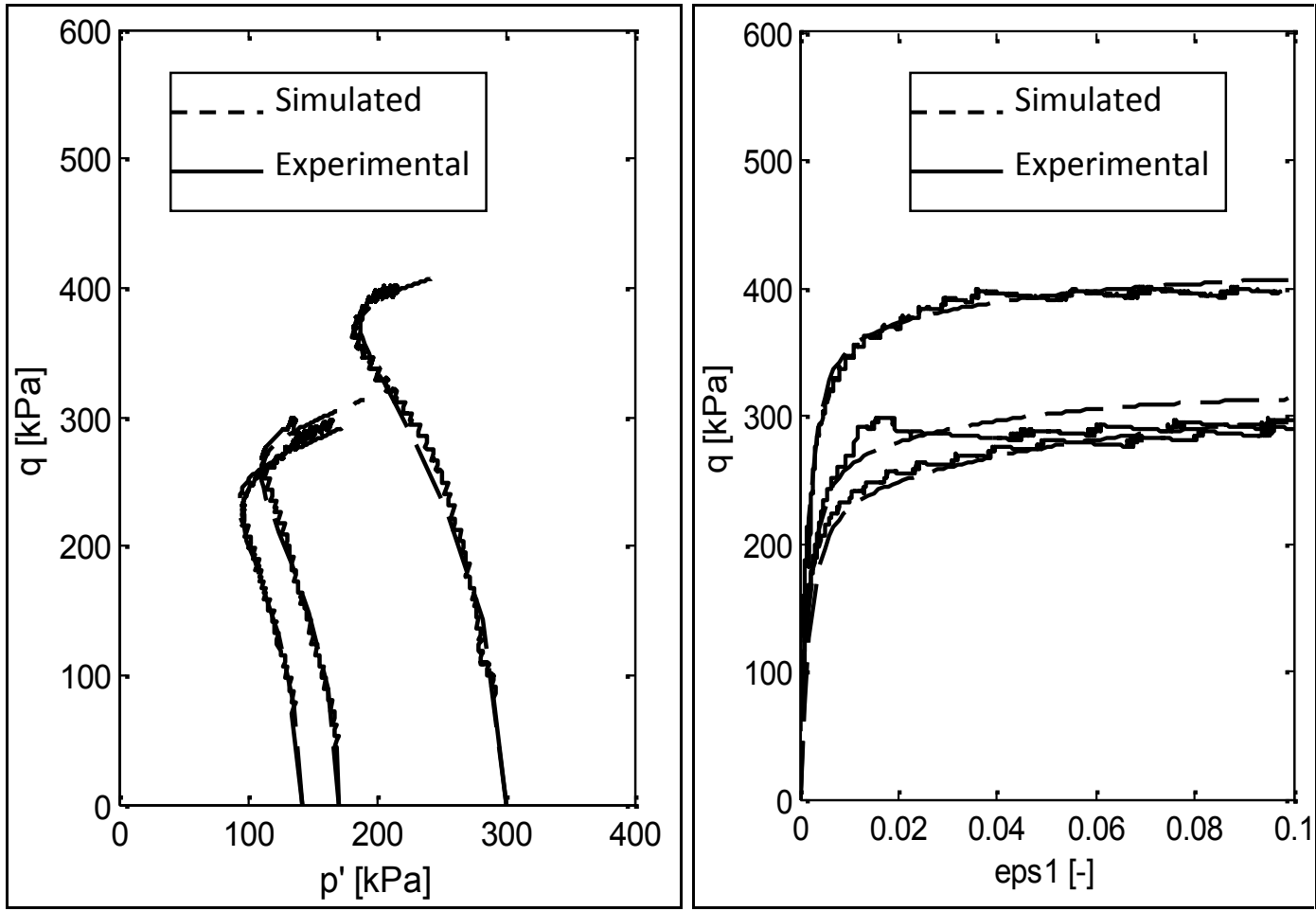

Figure 4: Simulation of triaxial compression - Mix 1

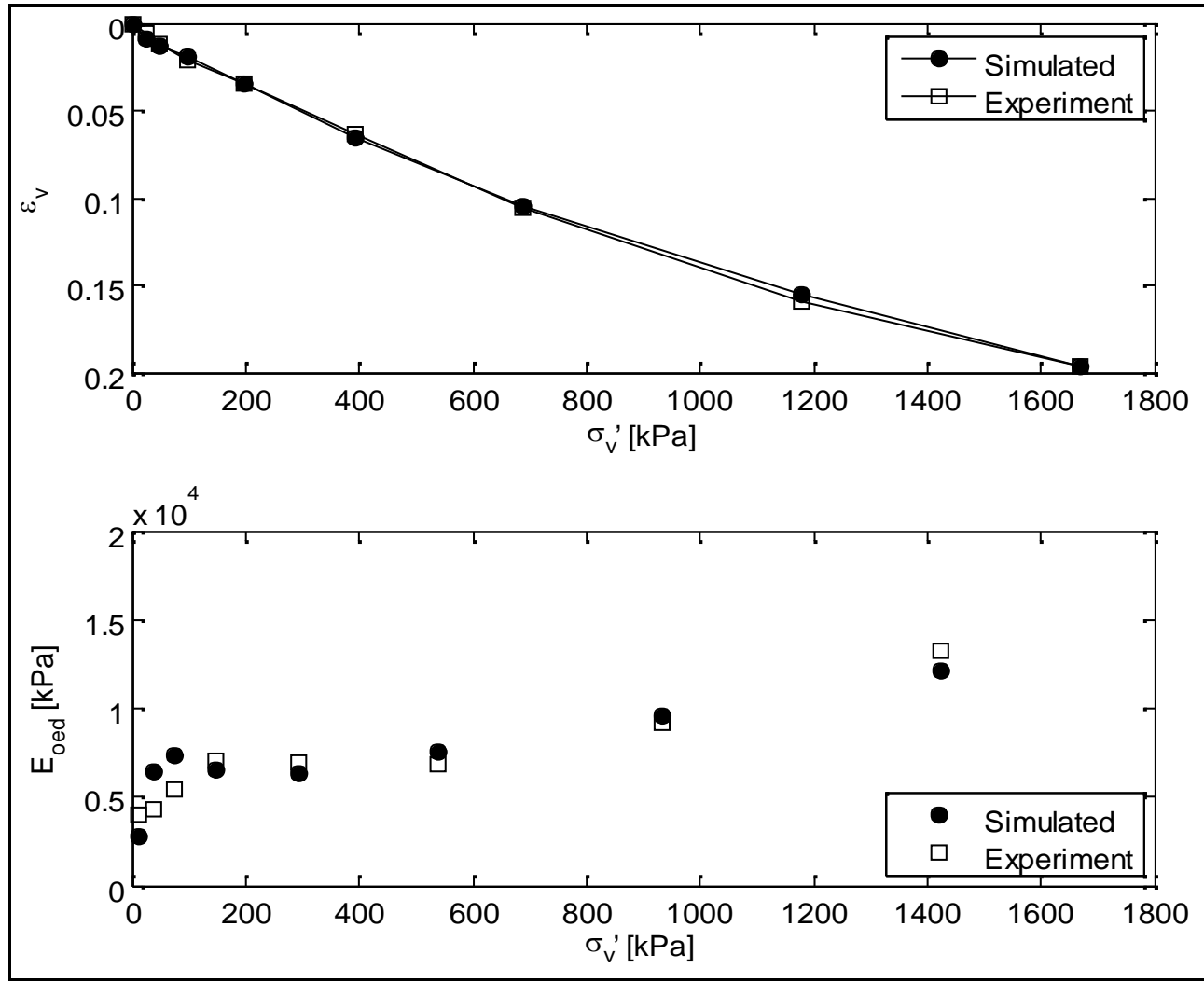

Figure 5: Simulation of oedometer strain and modulus - Mix 1 


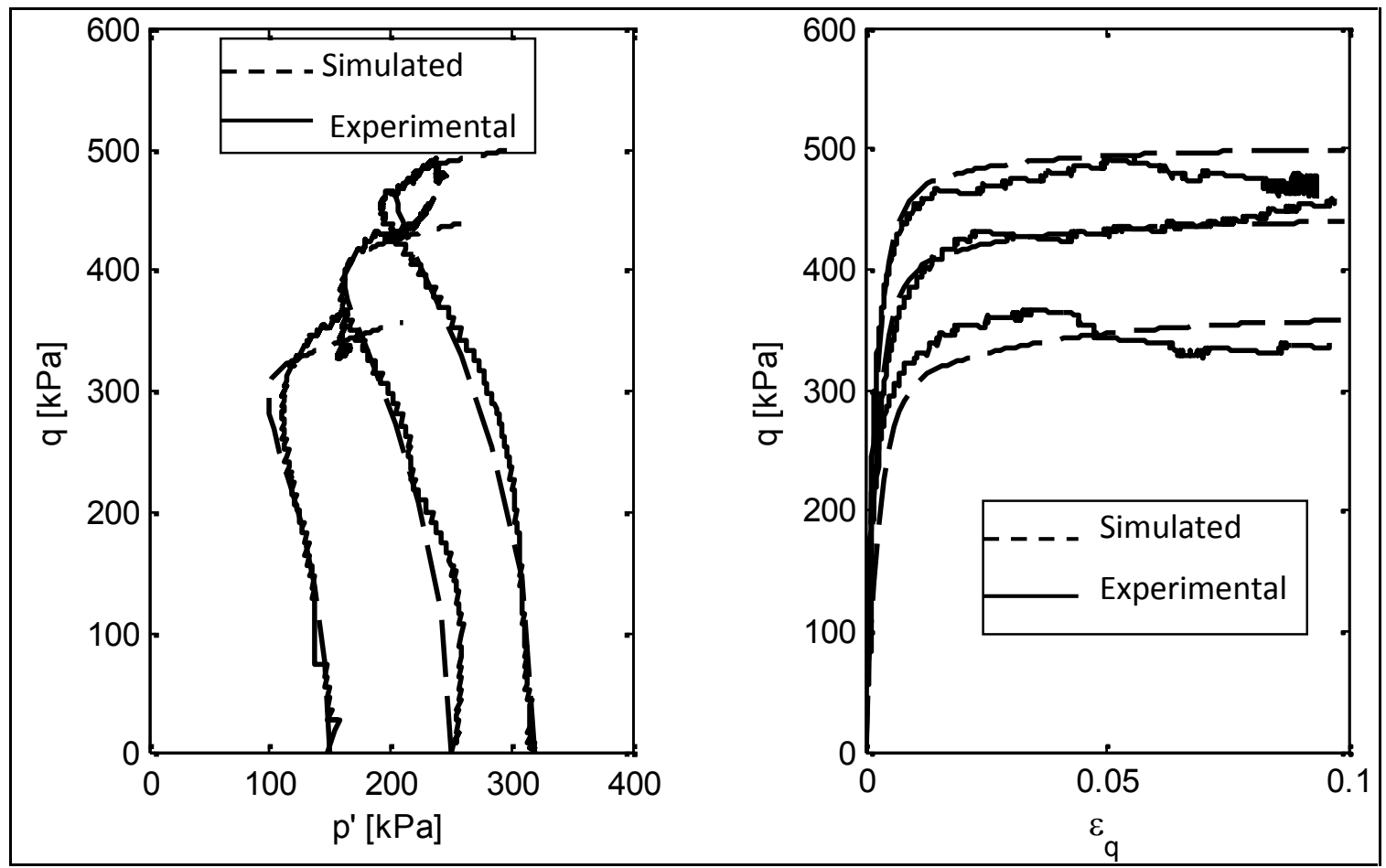

Figure 6: Simulation of triaxial compression - Mix 4

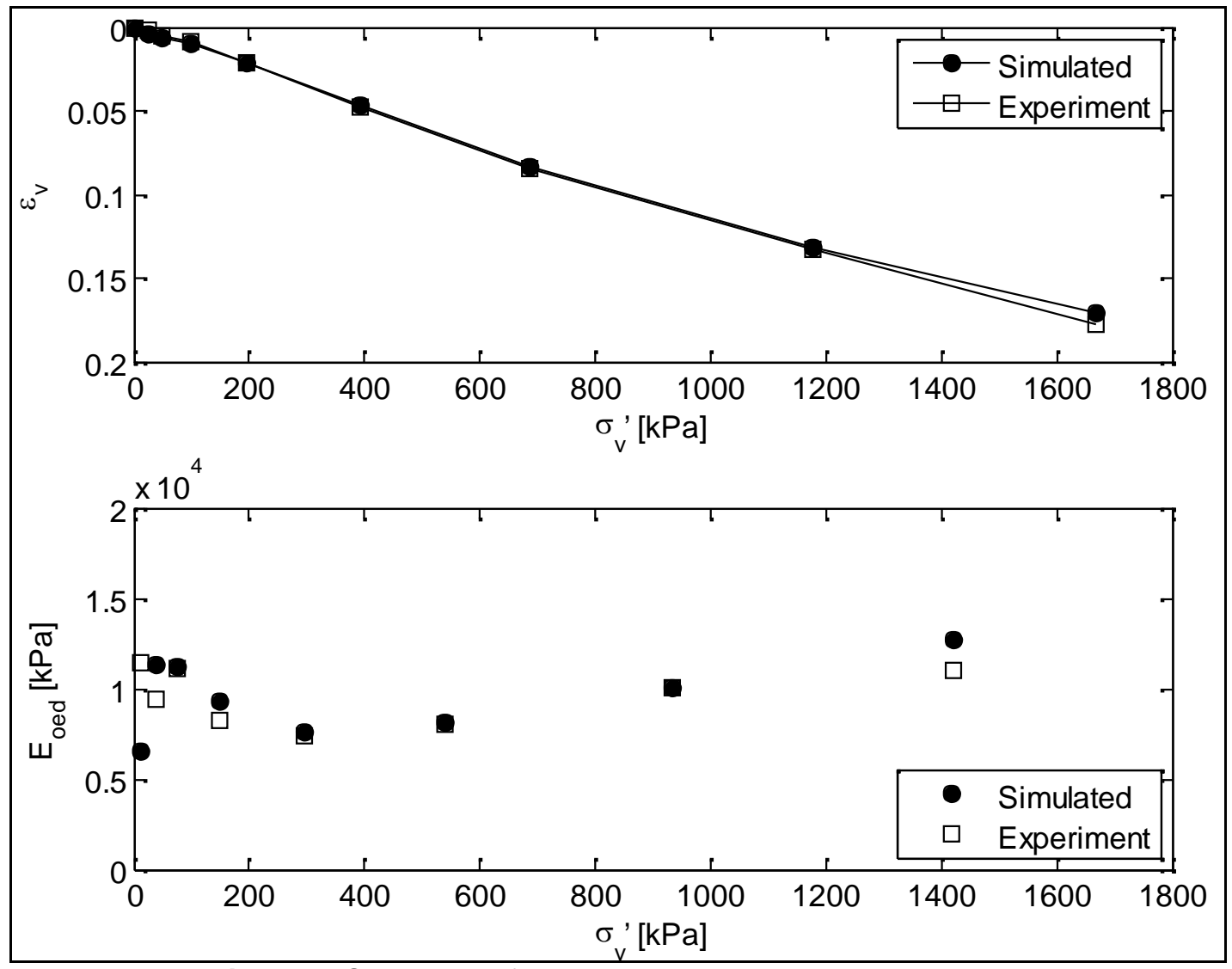

Figure 7: Simulation of oedometer strain and modulus - Mix 4 
The practically minor discrepancy observed between experimental data and simulations, mainly in the triaxial test plots (Figure 4 and Figure 6), can be explained by the localization problem in the laboratory experiments due to wedging and locking in the failure plane, typical of the brittle cemented quick clay samples (ref. Figure 8). All triaxial tests on stabilized quick clay revealed a substantial reduction in cohesion in the post-peak loading range, i.e. cohesion softening, but the angle of friction remained essentially unchanged (ref. Figure 9). Due to this phenomenon, the experimental stress-strain behavior for larger strains can therefore not be trusted. Broms (1999) suggests neglecting cohesion when the residual strain is used in the design of lime-cement columns.

\section{CONCLUSION}

A constitutive model for L-(C)-WSA stabilized quick clay has been formulated. The model (QUICKSTAB) has simulated well the overall geomechanical behaviour of stabilized quick clay and has shown good agreement with experimental results. The model parameters depend on the level of cementation (i.e. compressive strength) of the stabilized material and the confining pressure. With carefully selected parameters, the model functioned equally well for the tested four mixes. This suggests that the model may generally be applied to all similar mixes of cemented quick clay. However, an extensive parametric study should be done in order to thoroughly explain the behavior of the model. Different laboratory results should also be used for calibration of the proposed model. The isotropic cap surface should be validated by test following different stress paths and, if necessary, an anisotropic cap-surface may be included. Further, a nonassociated flow rule may be considered for the cap in order to control the levels of stress mobilization. The proposed additional tests should also be used to verify the calibration of the potential surface and the hardening rule for the cone (wedge).

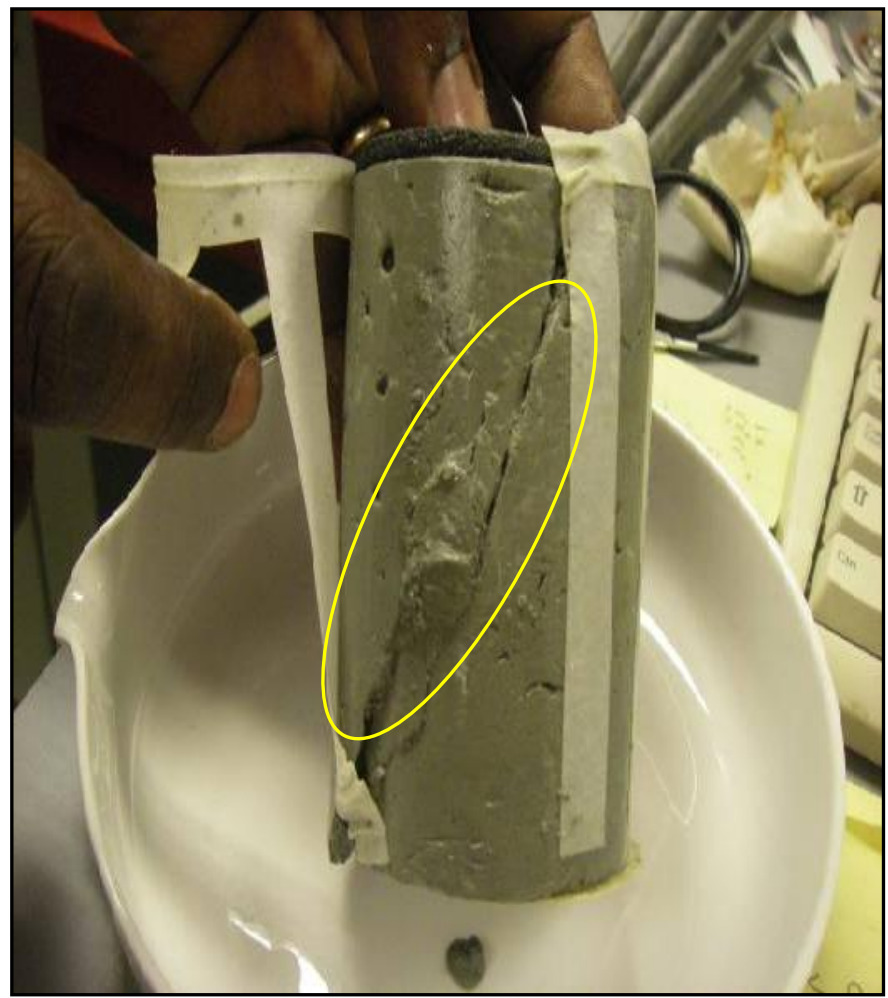

Figure 8: Wedging and locking in triaxial failure plane

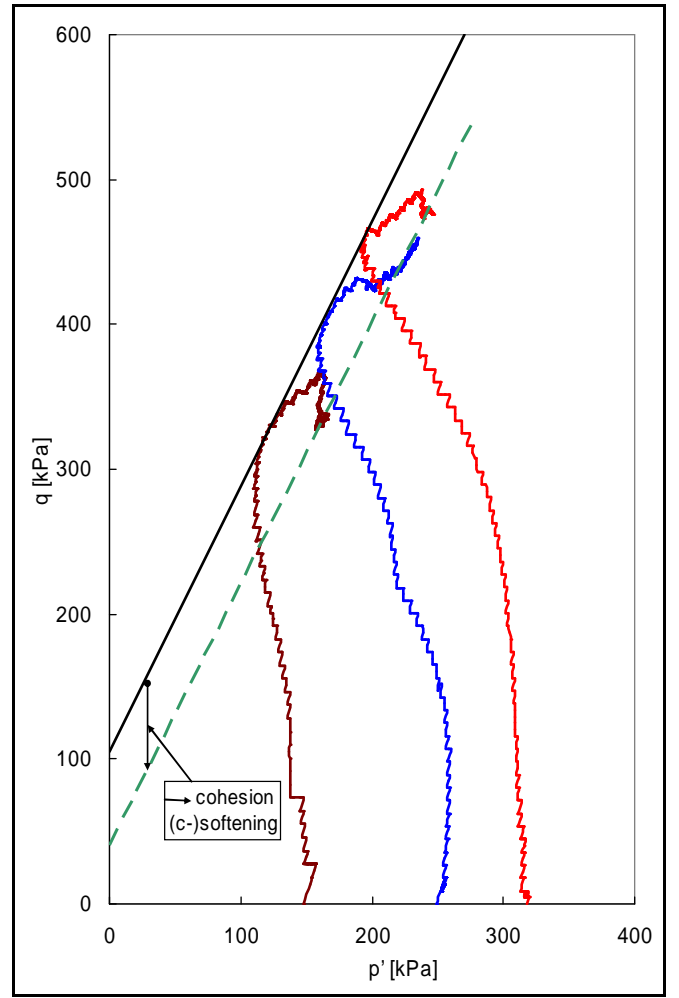

Figure 9: Typical triaxial results showing c-softening 


\section{ACKNOWLEDGMENT}

This research was carried out as a part of the Marie Curie Research Training Network "Advanced Modeling of Ground Improvement on Soft Soils (AMGISS)" (Contract No MRTN-CT2004-512120) supported by the European Community through the program "Human Resource and Mobility". The authors want to hereby acknowledge the financial support extended by the AMGISS project and the material support and labour assistance provided in the course of this research by the Norwegian University of Science and Technology (NTNU, Trondheim).

\section{REFERENCES}

Andrianopoulos, K. I., Papadimitriou, A. G and Bouckovalas, G. D., 2005. Bounding Surface Models of Sands: Pitfalls of Mapping Rules for Cyclic Loading, $11^{\text {th }}$ International Conference of IACMAG, Torino, Italy; June 19-24, 1, 241 - 248.

Baker, S., 2000. Deformation behaviour of lime/cement column stabilized clay. Swedish Deep Stabilization Research Centre. Rapport 7. Linköping, Sweden

Balasubramaniam, A. S and Buensuceso, B. R., 1989. On the overconsolidated behaviour of lime treated soft clay. Proc. 12th Int. Conf. on Soil Mechanics and Foundation Engineering. Rio de Jeneiro, Brazil. 2, 1335-1338.

Brinkgreve, R. B. J., Al-Khoury, R., Bakker, K. J., Bonnier, P. G., Brand, P. J. W., Broere, W., Burd, H. J., Soltys, G., Vermeer, P. A and Waterman, D., 2006. PLAXIS 2D version 8 user manual [online]. Available at www.plaxis.nl. [Accessed on February 22 ${ }^{\text {nd }}, 2008$ ]

Broms, B. B., 1999. Design of lime, lime/cement and cement columns. Keynote lecture. In H. Bredenberg, G. Holm, and B. B. Broms, (Ed.): Dry Mix Methods for Deep Soil Stabilization; Proc. Int. Conference on Dry Mix Methods for Deep Soil Stabilization; Stockholm, Sweden; 13-15 October (1999). 125-153.

Bujulu, P. M., 2008. Deep-mix Stabilization of
Quick Clay: A Potential Area for Utilization of Wastepaper Sludge Ash. PhD Thesis No. 2008:212. Norwegian University of Science and Technology, Trondheim, Norway

Dafalias, Y. F and Manzari, M. T., 2004. Simple Plasticity Sand Model Accounting for Fabric Change Effects, Journal of Engineering Mechanics, 130, (6): 622634.

Karstunen, M., Wiltafsky, C., Krenn, H., Scharinger, $F$ and Schweiger, H. F., 2006. Modelling the behaviour of an embankment on soft clay with different constitutive models. Int. J. Numer. Anal. Meth. Geomech., (in press), Published online in Wiley InterScience. Available at www.interscience.wiley.com DOI:10.100 $2 /$ nag.507 [Accessed on February $25^{\text {th }}$, 2008]

Kitazume, M., 2005. Filed and laboratory investigations, properties of binders and stabilized soil - State of practise report, Int. Conf. on Deep Mixing Best Practice and Recent Advances, Stockholm, Sweden, 660-684.

Kivelö, M and Broms, B. B., 1999. Mechanical behaviour and shear resistance of lime/cement columns. In $\mathrm{H}$. Bredenberg, G. Holm, and B. B. Broms, (Ed.): Proc. Int. Conference on Dry Mix Methods for Deep Soil Stabilization: Dry Mix Methods for Deep Soil Stabilization; Stockholm, Sweden; 13-15 October, 1999. pp. 125153.

Kwan, P. S., Bouazza, A., Fletcher, P., Ranjith, P. G., Shuttlewood, K., Balasubramaniam, A. S and Bolton, M., 2005. Behaviour of cement treated Melbourne and Southeast Queensland soft clays in deep stabilization works. Proc. Int. Conf. Deep Mixing Best Practice and Recent Advances; May 23-25, 2005; Stockholm, Sweden; 1.1, 101-110.

Roscoe, K. H and Burland, J. B., 1968. On the generalized stress-strain behavior of wet clay; Engineering plasticity pp. 535-609 Cambridge University Press 
Schanz, T., Veermer, P. A and Bonnier, P. G., 1999. The hardening soil model: Formulation and verification, Beyond 2000 in Computational Geotechnics - 10 Years of PLAXIS, Balkema, Rotterdam, ISBN 905809040

Søreide, O. K., 2003. Mixed hardening models for frictional soils, Ph.D. thesis 2003:21, NTNU, Trondheim, Norway

Wheeler, S. J., Näätänen, A., Karstunen, $\mathrm{M}$ and Lojander, M., 2003. An anisotropic elastoplastic model for natural soft clays. Canadian Geotechnical Journal 40, 403-418. 